\title{
Exploration on the Evaluation of Guangdong's Marine Ecological Resources Asset Value
}

\author{
Wu Yuxi*, Wang Yi \\ School of Economics, Guangdong University of Finance \& Economics, Guangzhou, China \\ Email address: \\ wu_yuxii@163.com (Wu Yuxi),wangy969@163.com (Wang Yi) \\ ${ }^{*}$ Corresponding author
}

To cite this article:

Wu Yuxi, Wang Yi. Exploration on the Evaluation of Guangdong's Marine Ecological Resources Asset Value. Science Discovery. Vol. 9, No. 4, 2021, pp. 139-144. doi: 10.11648/j.sd.20210904.12

Received: April 17, 2021; Accepted: May 19, 2021; Published: May 24, 2021

\begin{abstract}
Ecological resources as maintenance system components essential human survival environment, due to its special shape has so far failed to incorporated into the national economic accounting system, to avoid unreasonable under accelerate the Marine resource utilization policy leads to the deterioration of the ecological sustainability further excessive development of Marine resources, this article from the perspective of whole ecosystem services function definition of Marine ecological resources assets, Taking Guangdong Ocean as an example to evaluate the value of its ecological resource assets and discuss its importance to sustainable development. The results show that the service value of Marine ecological resources in Guangdong province is 619.541 billion yuan, and the stock value of ecological resources assets is 166543.28 billion yuan. Oceans played a significant role in primary production, accounting for $79.62 \%$, and also played an important role in species diversity, gene resources, disturbance regulation and climate regulation, accounting for $4.63 \%, 4.00 \%, 3.93 \%$ and $3.18 \%$ of the total value of resources, respectively. The regulating effect of Marine ecological resources can not be ignored, and pollution discharge still has a great impact on Marine water quality.
\end{abstract}

Keywords: Ecological Resource Assets, Marine Ecological Resources, Resource Value Assessment

\section{广东海洋生态资源资产价值评估探索}

武宇希*，王翊

广东财经大学经济学院, 广州, 中国

邮箱

wu_yuxii@163.com（武宇希），wangy969@163.com（王翊）

摘要：生态资源作为维持人类生存环境必不可少的系统要素, 由于其特殊的资产形态迄今并未能纳入国民经济核算系 统, 为避免在加速海洋资源利用政策下不合理过度开发海洋资源导致生态可持续能力进一步恶化, 本文从整体生态系 统服务功能角度定义海洋生态资源资产, 以广东省海洋为实例评估其生态资源资产价值探讨其对可持续发展的重要性。 结果表明: 广东省海洋生态资源服务价值为每年6195.41亿元，生态资源资产存量价值为166543.28亿元。海洋在初级生 产的作用上尤为显著, 达到 $79.62 \%$, 在物种多样性、基因资源、干扰调节以及调节气候功能中也发挥了较重要作用, 在资源总价值中占比分别为 $4.63 \% 、 4.00 \% 、 3.93 \% 、 3.18 \%$ 。海洋生态资源的调节作用不容忽视，污染排放等对海洋水 质仍有较大影响。

关键词: 生态资源资产, 海洋生态资源, 资源价值评估 


\section{1. 引言}

在我国经济长期快速增长进程中, 陆地自然资源大量 消耗导致资源短缺的压力, 对经济增长产生了明显的限制。 不断向深度和广度扩展的海洋资源开发利用成为未来我 国经济继续保持快速高质量发展新增长点。而海洋经济的 快速发展给海洋生态带来较大压力和影响。国家层面的发 展战略明确了海洋经济发展的基本方向。《中华人民共和 国国民经济和社会发展第十三个五年规划纲要》指出“科 学开发海洋资源, 保护海洋生态环境, 维护我国海洋权益, 建设海洋强国” [1]。十三五”期间, 我国海洋经济、科技成 果显著, 海洋生态系统保护修复迈出坚实步伐。2020年全 国政协“协调推进海洋资源保护与开发”双周座谈会再次 指出坚持生态优先, 实现海洋生态环境综合治理[2]。中国 海洋大学教授李京梅在自然资源部海洋环境经济核算研 讨会中表示, 生态环境持续恶化, 已成为中国海洋可持续 增长的制约性因素。生态环境问题实质上是在市场经济条 件下，现有的资源价格政策下资源配置的结果。海洋资源 的环境和生态价值无法进行市场表达是其重要根源。

自然资源无价观念的长期影响, 是资源浪费和破坏的 重要原因。特别是, 维持人类生存必不可少的生态系统要 素和生态功能, 由于其特殊的资产形态迄今并未被人们所 认识, 更未纳入国民经济核算系统。因此, 在当前加快海 洋自然资源开发利用的形势下, 本文明确提出海洋生态资 源的概念, 并以广东省为案例, 系统评估海洋生态资源资 产的价值，对完善自然资源资产核算体系，建立海洋自然 资源资产化管理的基础, 实现海洋自然资源资产保值增值 都具有重要意义。

\section{2. 研究区域概况}

广东位于我国大陆南部沿海, 北纬 $20^{\circ} 13^{\prime}-25^{\circ} 31^{\prime}$, 东 经109 $39^{\prime}-117^{\circ} 19^{\prime}$ 之间; 地处热带和亚热带气候过渡区, 是亚洲大陆东南缘南海北部地区海洋与陆地季风环流相 互作用较明显的地带, 其气候大部分属亚热带季风气候。 广东省年日照时数多, 雨量充沛。

广东省海域辽阔, 海域面积达到 41.9 万 $\mathrm{km}^{2}$, 占全省国 土总面积约 $69.88 \%$ 。入海河流众多, 海域环境质量总体保 持良好状态, 近岸海域水质总体优良, 有部分近岸海域环 境受陆源污染影响较大, 全省年均水质优良面积为 $89.5 \%$ [3]。且近年来广东海域水质年均优良面积比例呈上 升趋势。广东海洋生物资源丰富, 共有浮游植物406种、浮 游动物416种、底栖生物828种、游泳生物1297种、鱼类1200 多种 [4]。2020年夏季, 在对珠江口、大亚湾、雷州半岛珊 瑚礁、南澳岛四片海域开展的海洋生物多样性监测结果显 示多样性指数平均分别为 $1.94 、 2.63 、 2.86$ 和 $3.16[3]$ 。

\section{3. 海洋生态资源资产概念界定}

界定评估对象的内涵与外延, 是开展一项评估的前提。 特别是目前生态资源和生态资源资产概念还不统一、争论
较大的情况下, 给出一个较为完整的说明和定义, 非常必 要。

\section{1. 生态资源资产研究现状}

生态资源是指能为人类提供生态服务或生态承载能 力的各类自然资源, 以及各种由基本自然要素组成的生态 系统等, 包括土地、矿藏、森林、大气、水体等 [5-6], 是 区别于矿产资源的一种可更新自然资源[7]。生态资源提供 各种生态服务,这些生态服务为我们社会经济的发展以及 生存提供基本的保障。

刘国华等人较早提出生态资源资产一词, 认为生态资 源资产是生态资源实物量化的货币表现形式[7]。学者对这 一概念的认识是逐步深化延展的。从当前学者的研究来看, 可以将其定义划分为两类, 一类强调生态资产的价值体现 形式, 如张军连 [8]认为在一定时间和空间范围内的一切自 然资源、生态环境及其对人类的服务功能为生态资源资产。 侯鹏 [9]指出生态资产是用价值量衡量的生态系统为人类 社会提供的自然资源的有形服务产品和其他的无形服务 产品的集合。潘忠耀等[10]认为生态资产由隐形的生态系 统服务功能价值和有形的自然资源直接价值两部分组成。

另一类定义则强调生态资产的实体形式，陈百明等 [11]指出生态资产是所有者对生态系统实施生态所有权而 获取的服务效益和福利的生态景观实体。白杨等[12]认为 生态资产是指能为人类提供生态产品和服务的生态资源, 即生态系统资产,包括自然生态系统、人工生态系统及野 生动植物。高吉喜等[5]将生态资产定义为可为人类提供服 务和福利的生态资源与生态环境实体, 具有清晰产权和市 场交换价值, 是所有者财富和财产的重要构成部分。

从对生态资源资产评估研究来看, 对这一资产价值的 评估主要分为三类, 其一主流方法是在参考Costanza[13] 等研究分类成果的基础上, 采用相应的直接市场法、替代 价格法、成果参照法等方法对生态系统服务进行量化评估 [14-15]; 其二, 基于GIS技术及遥感监测数据, 利用CASA 模型、InVEST模型、ARIES等, 尝试对复杂生态系统进行 定量评估 $[10,16]$; 其三, 从生态学角度, 构建并量化相 应研究类型土地功能价值指标评价体系, 采用能值分析方 法, 量化评估相应功能价值[17]。

\section{2. 海洋生态资源与生态资源资产的定义及特点}

本文将海洋生态资源定义为生活在海中的生物群落 与环境共同组成的有一定结构和功能的生态系统。这个系 统的各组成成分, 可以分别划分为某类具体的自然资源, 但当这些组成成分以某种结构组成一个系统时, 这个系统 具有了其他任何单种自然资源不具备的功能。这些功能直 接或间接地服务于当前和未来人类生产和生活, 具有其他 自然资源提供服务时的性质和能力。更本质地说, 海洋生 态资源是海洋生态系统及其生态过程维持人类生存发展 与自然生态平衡的有序结构。这个结构具有整体性、多用 性、经济性、区域性和稀缺性等特点[18]。

海洋生态资源提供的服务总体上可称为生态服务。生 态服务的具体种类繁多, 并且随具体海洋生态系统结构的 
差异而不同。这里需要特别说明的是, 我们定义的生态资 源指生态系统的有序结构, 这个结构在生态系统运转过程 中发挥的生态功能主要是支撑服务和调节服务两大类, 而 不是一般研究中生态系统提供的全部四大类生态服务。在 以往的Costanza等学者的研究中, 海洋生态系统服务一般 分为四大类，即支持服务、调节服务、供养服务和文化服 务[13]。相较来看, 支持服务和调节服务是生态资源构成 的生态系统发挥作用时自身天然能够提供的功能和价值, 供给服务和文化服务价值均需通过社会、经济等其他要素 的投入才得以实现，故本文对生态资源价值的测算仅考虑 支持服务和调节服务两方面。海洋生态资源的主要功能包 括固碳释氧, 营养盐循环, 污染物净化, 物种多样性维持, 基因资源，提供初级生产，生物控制以及干扰调节功能。

不同于生态资源, 生态资产具有自然和经济双重属性。 生态资产具有的经济学属性为稀缺性、归属性、价值性和 可交易性等 [5]。生态资源转化为生态资产需要满足三个条 件:稀缺性、增值性和产权明晰[6]。海洋资源的总量是相 对有限的, 且随着经济社会发展, 海洋资源开发利用频繁, 海洋资源受损, 海洋生态资源本身具有的稀缺性特征; 增 值性即生态资源本质属性, 指在预期在当前或未来可以带 来经济效益; 产权明晰指生态资源的归属性, 被所有者控 制。综上, 海洋生态资源当前或未来能够产生经济效益, 且被某一经济体拥有或控制, 则海洋生态资源就具备了资 产性质，即海洋生态资源资产。由于海洋生态资源资产的 特殊性, 其产权具有归国家所有, 向全社会提供价值, 具 备经济、社会、生态三重效益, 且生态效益远大于经济、 社会效益。

\section{4. 广东海洋生态资源资产价值实际评估}

在对海洋生态资源资产价值评估方法进行梳理的基 础上, 本文以广东省海域为研究区域, 采用相应研究方法, 系统评估该海域海洋生态资源资产的价值。

\section{1. 海洋生态资源资产评估方法}

对海洋生态资源资产的评估应从其功能性的角度评 估其生态系统的服务价值。生态服务类型多样，但它们的 一个共同的性质是公共产品, 具有完全的外部性, 无法通 过市场获得其价格, 需要依照不同类型服务功能特征以采 取相应方法。从当前学者对于生态资源资产价值评估技术 来看, 主要分为直接市场评估技术、替代市场评估技术、 假想市场评估技术。

直接市场评估技术是指利用资源的市场价格来推定 评估其价值的一系列方法。在海洋生态资源是在相当成熟、 有序和规范的市场条件下销售的前提下, 市场价格能比较 准确地反映其价值时, 可以采用此评估技术。具体的方法 包括市场价值法、直接成本法、收益现值法、假设开发法 等，不同的评估方法可以配合使用。当待评估的资源根本 没有相应的市场, 即没有市场价格; 或者其现有的市场只 能部分地反映资源数量和质量变动的情况下, 直接市场评 估技术的应用受到限制，必须考虑采取其他的评估方法。
替代市场评估技术依据替代原理, 通过寻找那些能够 间接反映人类对海洋生态资源质量评价的商品或劳务, 通 过可替代的市场价格间接测算这些资源的价值的评估技 术。替代市场评估技术的基本假设是：观察到的价格反映 了购买者对一项产品或服务的整体估价, 这种估价包括了 有形的易于标价的部分和无形的环境效用。就目前市场的 发展水平来看, 有大部分的海洋资源是无法进行交易的, 并且这些海洋资源本身也存在无法交易的因素, 这种情况 下需要通过替代市场法进行价值评估。该技术具体包括替 代成本法、旅行费用法、影子工程法、享乐定价法等。

假想市场评估技术是目前世界较为流行的环境资源 评估技术, 通常以调查问卷为工具, 指在假设市场条件下, 通过调查潜在消费者对于某种生态资源的支付愿意或获 得补偿的意愿, 建立模型从而估计生态资源价值的技术, 包括条件价值法和选择模型法。对于有些海洋资源的价值, 既不能通过直接市场来衡量, 也很难找到能反应其真实价 值的替代市场予以量化评估。在这种情况下, 就只能通过 人为创造假想的市场来衡量其价值。由于该类评估技术评 价结果主观性较强, 评估结果会有较大偏颇, 在本文研究 中不予采取这类方法。

\section{2. 海洋生态资源资产评估分析}

本文根据广东省海域生态资源所提供的生态服务功 能, 采取相应的计算方法, 量化评估广东省海洋生态资源 价值, 在计算得到海洋生态资源流量价值的基础上, 假设 生态资源价值年纯收益不变, 采用收益还原法, 将资源流 量价值转换为生态资源资产存量价值。由于在收益还原法 中, 还原率为行业风险调整值及一年期存款利率代表的安 全利率之和, 而生态资源价值不存在行业风险调整值, 本 文替代采用安全利率与通胀率之和计算, 约为 $3.72 \%$ 。对 生态资源资产的八类生态服务功能进行评估。

\subsection{1. 固碳释氧服务价值}

生态系统影响区域和全球气候, 对大气环境的影响具 有正负两面。海洋生物通过吸收大气中的二氧化碳, 释放 氧气来调节大气湿度维持平衡。本文采用替代价格法计算 该价值。

$$
P=\left(1.63 C_{C_{2}}+1.20 C_{O_{2}}\right) X S
$$

$X$ 是指海域初级生产力, $\mathrm{C}_{\mathrm{CO}_{2}} 、 \mathrm{C}_{\mathrm{O}_{2}}$ 是指固定 $\mathrm{CO}_{2}$, 释 放 $\mathrm{O}_{2}$ 的成本, $S$ 为海域面积。常数项为, 生态系统每生产 $1 \mathrm{~kg}$ 干物质, 可固定 $\mathrm{CO}_{2}$ 、释放 $\mathrm{O}_{2}$ 分别为 $1.63 \mathrm{~kg} 、 1.20 \mathrm{~kg}$ 。

中国海域初级生产力平均约 $47 \mathrm{gc} /\left(\mathrm{m}^{2}\right.$.a)。当前国内制 氧成本约 400 元 $/ \mathrm{t}$, 国际碳交易价格约 321 元 $/ \mathrm{t}$ 。带入公式计 算得广东海洋年气候调节流量价值总计为约为 196.77 亿 元。

\subsection{2. 营养盐循环服务价值}

营养盐循环促进了营养盐无机与有机的转换, 不仅是 海洋生态系统的重要组成部分, 也是海陆大循环的重要一 环, 一定程度上对研究富营养化、赤潮等问题也有重要作 用。海洋中营养元素受生物影响最大, 关系最密切, 重要 
的还是氮、硅、磷, 在海洋学上称它们为营养元素。在对 海洋生态系统营养盐循环的功能价值评估时, 参考王静 [15]在海洋资源价值中评估方式, 用去除由海洋处理的含 氮磷等营养盐的成本替代。

$$
P=V_{N} C_{N}+V_{P} C_{P}
$$

$C_{N} 、 C_{P}$ 是 $N 、 P$ 去除成本, $V_{N} 、 V_{P}$ 是广东省海域 $\mathrm{N} 、 \mathrm{P}$ 的去除量。海洋生物中的浮游植物进行光合作用时, 按照 固定的比例吸收 $\mathrm{C} 、 \mathrm{~N} 、 \mathrm{P}$, 释放二氧化碳。生物学Redfield 比值, 海洋漂游生物对营养盐的吸收比例一般为 $\mathrm{C}: \mathrm{N}: \mathrm{P}=106: 16: 1$, 根据《中国海洋统计年鉴》, 广东海洋 年均固碳量约 2246.4 万吨, 计算得到地区 $\mathrm{N}, \mathrm{P}$ 控制量为 339.08 万吨、 21.19 万吨。生活处理污水成本, 含氮污水 1500 元/t, 含磷污水 2500 元/ $t[19]$, 计算得到广东省年营养盐循 环流量价值约为 56.16 亿元。

\subsection{3. 污染物净化服务价值}

污染物净化价值主要指对生态系统化学污染物、废弃 物处理的价值, 海洋资源处理化学需氧量、氮、磷以及石 油类、重金属类污染物的服务价值可以用人工去除被填海 域内接纳相应污染物的成本替代。本文根据实际污染物净 化测算, 即测算广东省海域处理污染废弃以保持海域生态 的能力以代表广东省海域净化污染物带来的服务价值。近 海海域废弃物处理的价值量为不同入海污染物数量与去 除污染物的成本的乘积。评估公式为:

$$
P=\sum\left(Q_{j} \times P_{i}\right)
$$

其中, $Q_{j}$ 为废弃物处理的物质量 $(\mathrm{t} / \mathrm{a}), P_{i}$ 为处理废 弃物单位价格（yuan/t）。

广东省年污染物入海总量 347.61 万吨, 主要成分中, 化学需氧量 287.45 万吨, 氨氮 3.93 万吨, 硝酸盐氮 48.53 万 吨, 亚硝酸盐氮 2.46 万吨, 总磷 4.51 万吨, 石油类 0.38 万 吨[20]。《排污费征收标准管理办法》显示, 石油类排污 价格 7000 元/t, COD去除成本为 4300 元 $/ t[14]$ 。由于营养盐 循环中计算了磷和氮的去污成本, 在此不予重复, 计算得 广东省污染物净化流量价值约为 123.87 亿元。

\subsection{4. 物种多样性服务价值}

物种多样性维持是指支撑生态系统正常运转的基础 性支持服务功能, 为生态系统向人类提供服务和生态福利 发挥着关键作用。受到数据限制, 采用成果参照及市场比 较法对该类价值进行评估。2009年国内海洋生物多样性维 持总价值约79.7亿元/年[21], 由于经济发展水平影响对于 该价值维持认知, 本文参考《中国统计年鉴》以广东省2019 年人均GDP与 2009 年全国人均GDP比值 3.6 作为调整系数, 可得年均物种多样性价值约为 286.92 亿元。

\subsection{5. 初级生产服务价值}

初级生产指无机营养性生物所进行的有机物的生产 [22]。本文参照当前认可度较高的评估方式, 根据海洋初 级生产力与软体动物的转化关系、软体动物与贝类产品重
量关系及贝类产品在市场上的销售价格、销售利润率等来 建立海域生境功能的价值评估模型:

$$
P=\frac{P_{0} E}{\sigma} \delta S P_{S} \rho_{S}
$$

其中, $P_{0}$ 是单位面积海域的初级生产力, $E$ 为初级生 产力转化为软体动物的转化率, $\delta$ 为贝类重量与软体组织 重量的比, $P_{s}$ 为贝类产品平均市场价格, $\rho_{s}$ 为贝类产品销 售利润率, $\sigma$ 为贝类产品混合含碳率, $S$ 为海域面积。

广东海域初级生产力 $47 \mathrm{gc} /\left(\mathrm{m}^{2} . \mathrm{a}\right)$, 海域 $10 \%$ 的初级生 产力会转化为软体动物 [23], 软体动物混合含碳率 $8.33 \%$, 各类软体组织与其外壳的平均重量比为 1:5.52[24], 2019 年广东全年贝类市场均价约 18.9 元 $/ \mathrm{kg}$, 在 $20 \%$ 产品的销售 利润水平下, 得到广东省提供初级生产年价值约4932.85 亿元。

\subsection{6. 基因资源服务价值}

基因资源指海洋生物为人类提供的遗传基因资源, 其价值与海域内生物物种数直接相关。参考近年来对生 态系统基因资源价值的评价方法, 本文采用成果参照法 对该价值进行评估, De Groot (2002) 研究表明, 生态 系统提供基因资源价值为(6 112) $\$ / \mathrm{hm}^{2}$ 年 [14]。广东多处 亚热带区域, 海洋资源相对丰富, 取De Groot基因资源 价值最高值 $80 \%$ 作为区域海域基因资源价值 $[25]$, 约每平 方公里 5.91 万元, 得到广东省海域基因资源流量价值约 为 247.63 亿元。

\subsection{7. 生物控制服务价值}

生物控制指通过生物种群的营养动力学机制, 海洋生 态系统所提供的控制有害生物, 降低相关灾害损失的服务 [26-27]。由于数据受限, 采用成果参照法对这一价值进行 评估, Costanza指出海岸带生物控制价值为 38.0 美元/ ( $\mathrm{hm}^{2}$.a ) [13], De Groot在2002年研究得到海洋生物控制 价值为 $2-78$ 美元/ $\left(\mathrm{hm}^{2} . \mathrm{a}\right)$ 。参考吴姗姗等 $[14]$ 取均值方 式, 得到生物控制价值约 39.0 美元/ $\left(\mathrm{hm}^{2} . \mathrm{a}\right)$, 以一美元 兑换6.6元人民币汇率换算得约 25740 元/ $\left(\mathrm{km}^{2} . \mathrm{a}\right)$ ，广东 省生物控制流量价值为 107.85 亿元。

\subsection{8. 干扰调节服务价值}

干扰调节价值即指海洋生态系统提供对人类生存环 境波动的响应、调节服务。对这一价值的评估来看, 学 者主要采用Costanza[13]评估结果调整计算, 海域每年所 提供干扰调节的服务价值为 $88 \$ / \mathrm{hm}^{2}$ 。同样以 $6.6: 1$ 的汇 率换算得 58080 元 $/ \mathrm{km}^{2}$, 即广东省干扰调节价值为 243.36 亿元。

\section{3. 生态资源资产价值换算结果}

以上各项流量价值之和即为海洋生态资源资产的年 流量价值。通过收益还原法, 将生态资源资产服务流量价 值转换为其存量价值。见表 2 。广东省海洋生态资源服务 价值为每年 6195.41 亿元, 生态资源资产存量价值为 166543.28亿元。 
表1 广东省海洋生态资源资产价值评估结果。

单位: 亿元/年、亿元

\begin{tabular}{llll}
\hline 价值类型 & 服务流量价值 & 资产存量价值 & 占比 \\
\hline 气候调节 & 196.77 & 5289.52 & $3.18 \%$ \\
营养盐循环 & 56.16 & 1509.68 & $0.91 \%$ \\
污染物净化 & 123.87 & 3329.84 & $2.00 \%$ \\
物种多样性 & 286.92 & 7712.90 & $4.63 \%$ \\
初级生产 & 4932.85 & 132603.49 & $79.62 \%$ \\
基因资源 & 247.63 & 6656.72 & $4.00 \%$ \\
生物控制 & 107.85 & 2899.19 & $1.74 \%$ \\
干扰调节 & 243.36 & 6541.94 & $3.93 \%$ \\
合计 & 6195.41 & 166543.28 & $100 \%$ \\
\hline
\end{tabular}

\section{5. 评估结论}

本文对于生态资源资产的测算为广东省全部海洋生 态资源资产完全发挥价值的结果, 即海洋生态资源资产价 值上限。综合来看, 广东省生态资源资产流量价值约 6195.41 亿元/年, 约占2019年广东省海洋经济总产值的 $29.42 \%$, 可见, 广东省海洋生态资源资产价值不容小㱆, 其中, 海洋在初级生产的作用上尤为显著, 达到 $79.62 \%$, 在物种多样性、基因资源、干扰调节以及调节气候功能中 也发挥了较重要作用, 在资源总价值中占比分别为 $4.63 \%$ 、 $4.00 \% 、 3.93 \% 、 3.18 \%$ 。可见，在调节和支持作用中，广 东海洋生态资源以支持作用为主, 在全球气候异常变化的 形势下, 海洋生态资源带来的调节作用不容忽视。另外, 从当前评估结果及海洋生态环境变化现状来看, 海洋生态 资源的净化作用发挥并不显著, 而废水废气等污染物的排 放是导致海洋水质变化的重要原因之一。近岸海域水质改 善成效还不稳固, 陆源污染排放量仍然较大; 海洋生态系 统脆弱等问题仍是 “十四五”期间较大挑战, 因此, 陆海污 染防治、保护海洋生态、生态修复、全面提升海洋监管效 能是当务之急。

2011年李志勇 [25]等人按照Costanza等人四种服务的 分类方法对 2009年广东省海洋生态系统服务价值进行了 评估, 本文剔除其中供给服务和文化服务价值结果, 并计 算单位面积价值以剔除面积差异影响与李志勇等人测算 结果进行对比, 广东省2009年海洋生态服务价值每年约 111.91 亿元 $/ \mathrm{km}^{2}$, 广东 2019 年度海洋生态资源价值为 147.86 亿元 $/ \mathrm{km}^{2}$, 可见广东省单位面积海洋生态资源资产 价值10年间有一定程度提高, 其系统性服务功能作用的发 挥, 对维持区域生态系统平衡稳定以及支撑经济社会可持 续发展具有重要意义。

海洋生态资源是重要的海洋资源构成。自然资源部指 出, 海洋对整个地球生物圈价值贡献达到了 $60 \%$ 以上, 生 态资源资产价值的实现是海洋资源可持续的关键。

近年来广东海洋资源的过度开发与不合理利用, 使海 洋污染破坏严重, 生态灾害频发, 威胁整体海洋生态系统。 生态资源资产价值的实现是长期系统性的艰辛任务, 广东 省应对海洋生态资源资产价值充分重视, 在已有针对生态 资源资产价值实现的有益探索基础上, 坚持从生态系统的 稳定性出发, 加强海洋资源监管、推动海洋生态系统修复, 积极推动生态资源资产引入市场服务社会, 实现生态资源 资产资本化, 最大化利用海洋生态资源的同时提高综合效
益, 实现国有资产的保值增值, 实现区域财富增加和生态 系统稳定循环增值双赢。

\section{致谢}

本文为广东省海洋经济发展专项资金 (海洋六大产业) 项目《广东省海洋自然资源资产评估体系构建与案例研究》 （项目编号：GDNRC2020069）的成果之一。

\section{参考文献}

[1] 《中华人民共和国国民经济和社会发展第十三个五年规划 纲要》 $[R]$ 十二届全国人大四次会议, 2016.03 .

[2] 中国人民政治协商会议全国委员 会.http://www.cppcc.gov.cn/zxww/2020/11/05/ARTI1604543 493233184.shtml.

[3] 广东省生态环境厅。《2020广东省生态环境状况公 报》.http://gdee.gd.gov.cn/attachment/0/419/419194/3266052 .pdf.

[4] 《广东省海洋功能区划2011-2020》http://www.gd.gov.cn/ gkmlpt/content/0/141/post_1416广东人民政府网http://www. gd.gov.cn/gdgk/sqgm/201805/t20180517_270421.htm.

[5] 高吉喜,李慧敏,田美荣.生态资产资本化概念及意义解析 [J]. 生态与农村环境学报,2016,32(01):41-46.刘国华,傅伯杰.生 态区划的原则及其特征[J]. 环境科学进展, 1998(06):68-73.

[6] 胡熠,黎元生. 论生态资本经营与生态服务补偿机制构建 [J]. 福建师范大学学报(哲学社会科学版),2010(04):11-16. 高吉 喜, 范小杉.生态资产概念、特点与研究趋向 [J].环境科学研 究,2007(05):137-143.

[7] 刘国华,傅伯杰.生态区划的原则及其特征[J].环境科学进 展, 1998(06):68-73.

[8] 张军连,李宪文.生态资产估价方法研究进展 []].中国土地科 学,2003(03):52-55.

[9] 侯鹏,王桥, 申文明, 翟俊,刘慧明,杨旻.生态系统综合评估研 究进展: 内涵、框架与挑战 [J]. 地理研 究,2015,34(10):1809-1823.

[10] 潘耀忠,史培军,朱文泉,顾晓鹤,范一大,李京.中国陆地生态 系统生态资产遥感定量测量 [J]. 中国科学 (D辑: 地球科 学),2004(04):375-384.

[11] 陈百明,黄兴文.中国生态资产评估与区划研究[J].中国农业 资源与区划,2003(06):23-27.

[12] 白杨,李晖,王晓媛,Juha M.Alatalo,江波,王敏,刘文俊.云南省 生态资产与生态系统生产总值核算体系研究 [J].自然资源 学报,2017,32(07):1100-1112.

[13] Costanza R, d' Argee R, Groot R, et al. The Value of the World's Ecosystem Services and Natural Capital [J]. Nature, 1997(5): 253-260. 
[14] 吴姗姗,刘容子,齐连明,梁湘波.渤海海域生态系统服务功能 价值评估[J].中国人口·资源与环境,2008(02):65-69.

[15] 王静, 海洋资源价值评估理论与方法研究[D]. 南京师范大学, 2006.

[16] 包玉斌,李婷,柳辉,马涛,王怀香,刘康,沈茜,刘心浩.基于 InVEST模型的陕北黄土高原水源涵养功能时空变化 [J].地 理研究,2016,35(04):664-676.

[17] 马凤娇,刘金铜. 基于能值分析的农田生态系统服务评估 — 以 河北省栾 城县为 例 [J]. 资源科 学,2014,36(09):1949-1957.

[18] 王松需.生态经济建设大辞典[M]. 江西科学技术出版社, 2013.

[19] 张华,康旭,王利等.辽宁近海海洋生态系统服务及其价值测 评 [J].资源科学, 2010,32(01):177-183.

[20] 广东省生态环境厅.广东省海洋环境状况公 报.http://gdee.gd.gov.cn/hjzkgb/content/post_2466175.html.
[21] 王栋.海洋生物多样性维持的经济价值研究[D].中国海洋大 学, 2012 .

[22] 陈英旭主编,环境学, 中国环境科学出版社, 2001年03月第 1 版,第36页.

[23] 田朋, 海洋资源价值评估及应用研究[D].河北大学, 2016 .

[24] 卢振涁,杜琦,颜尤明,刘伟斌.厦门沿岸海域贝类适养面积和 可养量的估算 [J].台湾海峡,1999(02):3-5.

[25] 李志勇,徐颂军,徐红宇, 蔡霞.广东近海海洋生态系统服务功 能价值评估[J].广东农业科学,2011,38(23):136-140.

[26] 詹文欢. 广东省海洋环境资源基本现状 $[\mathrm{M}]$. 海洋出版社, 2013.

[27] 王其翔,唐学玺.海洋生态系统服务的内涵与分类 $[\mathrm{J}]$.海洋环 境科学,2010,29(01):131-138. 